\title{
Measuring the Performance of University Technology Transfer through the estimation of Invention Disclosure Life: Focus on Urban Marginal Area
}

\author{
Stefano De Falco \\ University of Naples Federico II, Italy
}

\begin{abstract}
With the growing competition in a globalized world, universities are seen as the key organizations and supporters in the national innovation system (Audretsch et al. 2006). Thus, national and regional policy makers try to set incentives for innovations and to increase the innovative potential of universities and to use it effectively. A large and diverse literature analyzes the importance of universities within the regional and national innovation system (Mowery and Sampat 2005; Cosh and Hughes 2010; Audretsch et al. 2011), often highlighting the necessity of separate and specialized organizational units to manage industry-university collaborations (Link et al. 2008; Fritsch and Lukas 2001). Within this process, TTO are seen as the institutionalized way to transport and canalize the ideas, inventions and innovations of academic researchers into the (regional) industry and society (van Ledebur 2008; Meoli et al. 2011; Gonzàles-Pernia et al. 2011). Thus, given the importance attached to TTO within this process, policy makers and university management should be interested in the performance differences of TTO.During its activity, after a certain period, we can define as the "performance life", continuing to try to transfer to the industry the same technologies leads to heavy financial loss to the TTO, because innovations and their commercialization, based on networking effects between the academic researchers and the industry, with TTO as the hub of the university-industry, determine market saturation.In this article, we deal with estimation of "performance life" for the invention disclosures by TTO and determination of replacement plan. This "performance life" has been modeled using a piecewise linear-quadratic TTFR function. A computational procedure is proposed for estimation of performance life. Hülsbeck et al., (2011) used the number of invention disclosures as a performance measure, to analyze how variance in performance can be explained by different organizational structures and variables of TTO. In this paper we refer to the same performance measure to be monitored.The approach of the present study declines the exposed issue to the specific case of marginal urban area. Results of an empirical analysis are proposed. It regards to a real case, based on the analysis of the impacts of the recent settlement of a research center, the center Cesma of the University of Naples Federico II, in marginal east area of the city of Naples, in which the local administration has decided to implement requalification actions. Finally, a technology transfer replacement plan for TTO is derived. This proposed model and solution may be appealing to geographers, managers and technology transfer agents since the graphs and tables proposed could be reproduced in a number of standard optimization software.
\end{abstract}




\section{INTRODUCTION}

A TTO is expected to perform its intended function for a certain number of technology transfer instances (TTI) referred to a certain specific invention disclosure, we say ID*. The performance life of a TTO is designated by the number of such TTI it has performed with regard to this particular ID*.

To transfer to the industry the same invention disclosure leads to heavy financial loss to the TTO, because innovations and their commercialization, based on networking effects between the academic researchers and the industry, with TTO as the hub of the university-industry, determine market saturation.

On the other hand, an early replacement of an invention disclosure leads to its underutilization (and hence additional technology transfer cost). In the absence of proper knowledge on the performance life of each invention disclosure, the operators carry out audit (in between TTIs) in order to arrive at the decision for its replacement. A suitable replacement plan will thus help in reducing technology audit cost through lesser audit, a plausible approach to the development of a replacement plan is based on the estimate of the wearout point of the corresponding TTFR rate function. Wear-out point of the TTFR rate function is defined as a change-point. Generally, a change-point refers to the time point when TTFR rate pattern changes abruptly. The literature on estimation of changepoint is quite rich. For reference, see Gombay (2000), Loader (1991), Nguyen et al. (1984), and Rukhin (1997). Motivation for this problem can be found in various applications. For instance, Mathews and Farewell (1982) studied the effectiveness of a new therapy in terms of reduction in relapse rate. Basu et al. (1988) (hereafter referred to as BGJ) deal with change-point estimation in the context of optimal burn-in strategy in reliability engineering. Gürler and Yenigün (2002) proposed a method for detection of AIDS (acquired immune deficiency syndrome) in HIV-infected patients. A large majority of these articles consider piecewise linear TTFR rate function (with or without a jump at the change-point). The solution procedures are developed using likelihood method or bayesian approach. A common feature of these articles is the assumption that TTFR rate is well known. On the contrary, a practical problem generally calls for modeling and estimation of TTFR rate. This article is organized as follows. We refer to the approach proposed, in other field, by D.K. Manna (Manna 2004). We discuss the basic data on performance life and study the pattern of empirical TTFR rate function. Lifetime is modeled using a piecewise linearquadratic TTFR function. We propose a computational procedure for the estimation of associated parameters and for derivation of replacement plan of a certain invention disclosure (ID*). We also discuss the results of maximum likelihood method and the procedure of BGJ and contrast them with that of the proposed method.

\section{TECHNOLOGY TRANSFER PERFORMANCE METRICS}

The performance of university TTOs has been studied by many investigators, and a wide range of metrics has been selected to assess their performance (Tseng and Raudensky, 2015).

The rapid increase in university technology transfer has attracted attention in the academic literature (Rothaermel et al. 2007; Carlsson and Fridh 2002; Jensen and Thursby 2002; Di Gregorio and Shane 2003; Baldini 2006; Anderson et al. 2007; Thursby and Thrusby 2007). This emerging literature is interdisciplinary, with contributions from scholars in many disciplines, such as economics, sociology, political science, public administration, engineering, and in several fields within management, such as strategy, entrepreneurship, human resource management, and technology and innovation management. There is also some international evidence for this phenomenon. Due to the complexity of the issues raised by the rise of 
technology transfer at universities, many authors have employed qualitative methods (De Falco 2012, 2014) to address key research questions (Vinig and Lips 2015).

Many studies have shown that a great deal of TTOs operate inefficiently. Some studies have been conducted to understand the underlying deficiencies. When we try to assess the ratio of each output, then we start to question the effectiveness of university technology transfer. A simple calculation of ratios of research expenditures per invention disclosure and licensing income dollars may at first glance lead a sceptic to question the effectiveness of university technology transfer. Heher (2006) provides a forecast of the income through university innovations. His finding of expected exponential increase also justifies exploration of the field. This issue of efficiency has been explored by using different methods. University research and its transfer to industry has been a topic of interest in the management of technology literature over decades (Anderson et Al. 2007).

We can see the literature grouped under the following titles: Organizational structures. Regional or international comparisons/case studies. Impacts of university research. Tangible outputs of university research (patents, licenses, spin-offs). Efficiency of university research transfer. Several researchers focused on the organizational issues. Siegel et al. (2003) explored such organizational structures of the TTOs linking them to their productivity suggesting that the most critical organizational factors for productivity TTOs in research universities are faculty reward systems, TTO staffing/compensation practices, and cultural barriers between universities firms. Rasmussen et al. (2006) explored initiatives provided by the universities to promote commercialization of university knowledge and identified coordination a challenge. McAdam et al. (2005) provide such a coordination model for university innovation centers. They analyze licensing and business building processes. Chapple et al. (2005) indicated that there is a need to increase business skills and management capabilities to TTOs. Thursby and Kemp (2002) also explored efficiency of university technology transfer by looking at the organizational issues. Siegel and colleagues studied similar issues (Siegel et al., 2003, 2004) also studied similar issues. Their focus has been the impact of organizational characteristics and the implications for education. They make recommendations based on the barriers identified in the UTT efficiency and effectiveness processes such as culture clashes, bureaucratic inflexibility, poorly designed reward systems, and ineffective management of TTOs. Lowe (2006) proposes a theoretical model to illustrate how the inventor know-how affects whether the inventor starts a firm to develop her idea or licenses an invention to an established firm for development. This model is then used to analyze the role and impact of a university TTO on this process to understand how TTOs may both positively and negatively impact the transaction. Leitch and Harrison (2005) explored the dynamics of the spin-off phenomenon with a focus on the TTO and they propose a wider role for such offices to be more efficient. Lopez (1998) explored different ways universities can get organized to improve the research efficiency. This group of literature supports our hypothesis that there are efficiency issues while transferring technology out of the university environment. We also see studies comparing different approaches or regions Goldfarb and Henrekson (2003) and Feldman et al. (2002) studied different policies for transferring university technology. Di Gregorio and Shane (2003) explored differences among universities in commercialization of technologies. Colyvas et al. (2002) studied case studies of commercialization of university inventions. Lee and Win (2004) explored three university research centers in Singapore concluding that coordination among university center, industry and government is one of the key success factors. OwenSmith et al. (2002) compared US and European practices in terms of university industry relations. Other studies focused on individual cases to explore similar issues. Zucker et al. (2002) looked at the efficiency of university technology transfer through a biotechnology case study. Lopez-Martinez et al. (1994) found out that in developing countries specifically in 
Mexico both academia and industry have implicit cultural dissimilarities which directly affect current or potential cooperative liaisons. The industry-academic interdepencies in Germany have been well studied (Meyer-Krahmer and Schmoch, 1998; Beise and Stahl, 1999). Their research findings indicate that there are certain requirements to be met by both parties to have successful long term collaborations. Boyle (1986) focused on the technology transfer between universities and the UK offshore industry; Corsten (1987) reviewed industryuniversity collaborations in 225 enterprises; and Goldhor and Lund (1983) provided a detailed analysis of transfer of a text to speech reading machine from MIT into industry. This group of literature verifies the efficiency issue further by adding another dimension of variance. We see that organizational, cultural and regional differences can make a difference. Some other studies focused on the impact of university research. Feller et al. (2002) and Cohen et al. (2002) specifically explored the impact of university research on industrial innovation. Shane and Stuart (2002) studied the resulting start ups through university research. Siegel et al. (2003) concluded that science university parks do not have significant impact on research productivity. Bennet et al. (1998) focused on university-industry collaboration for technology transfer in poorer regions of the United Kingdom. Such collaborations are reported to be successful and help local economies. Studies that focused on exploring the efficiency through studying their tangible output are found frequently in relevant literature. Trune and Goslin (1998) studied performance of the TTOs from a profit/loss analysis perspective. Their results indicate that such centers are profitable and are acting as significant economic drivers. Berman (1990) also provided evidence on the economic impact of industry funded university R\&D. Several studies (Agrawal and Henderson, 2002; Mowery et al., 2002; Shane, 2002) have specifically explored patenting within the universities. Geuna and Nesta (2006) fear that the increase in university patenting exacerbates the differences across universities in terms of financial resources and research outcome. Also, because of international property regulations (IPRs) there is a tendency for universities and academics to limit disclosure of materials and information, therefore helping to foster growing commercialism and competition among universities and dampen open science and knowledge transfer (Sampat, 2006). Mazzoleni (2006) presents a model of R\&D competition based on a university invention where appropriability conditions are defined by the patentability of downstream innovations and imitation opportunities. He concludes that university licensing royalties are therefore a poor gauge of social welfare gains from university patenting.

\section{DATA COLLECTION AND PRELIMINARY ANALYSIS: FOCUS ON EAST AREA OF NAPLES}

It is customary to maintain a life-history data base for every invention disclosure. This contains information on its life (i.e., the cumulative number of completed TTIs, where for completed we refer to those TTIs who have generated a contact link of interest with the potential users), in addition to other particulars such as dates of different technology transfer phases in which it's involved.

The Research Centre Cesma of the University of Naples Federico II, on which in based the proposed analysis, rises from 2012 in the ex former Cirio in San Giovanni in Teduccio, district of the east area of Naples (figure 1), that is a marginal no-tax area in which local government decided to invest to regenerate it through industries and research centres. An area of 200,000 quare meters that hosts classrooms, laboratories, libraries, departmental studies and conference center, with the aim to revaluate spaces, in a logic of urban regeneration of the coastal strip of Naples and suburbs.

CESMA is the Center for Advanced Metrological Services of the University Federico II, in which pre-existing laboratories network with new laboratories to perform measurement activities in 
several different fields of Engineering, Physics, Chemistry and Biology. The Centre CESMA come as node connection between the University Federico II and the industries and enterprises of the east urban area of Naples.

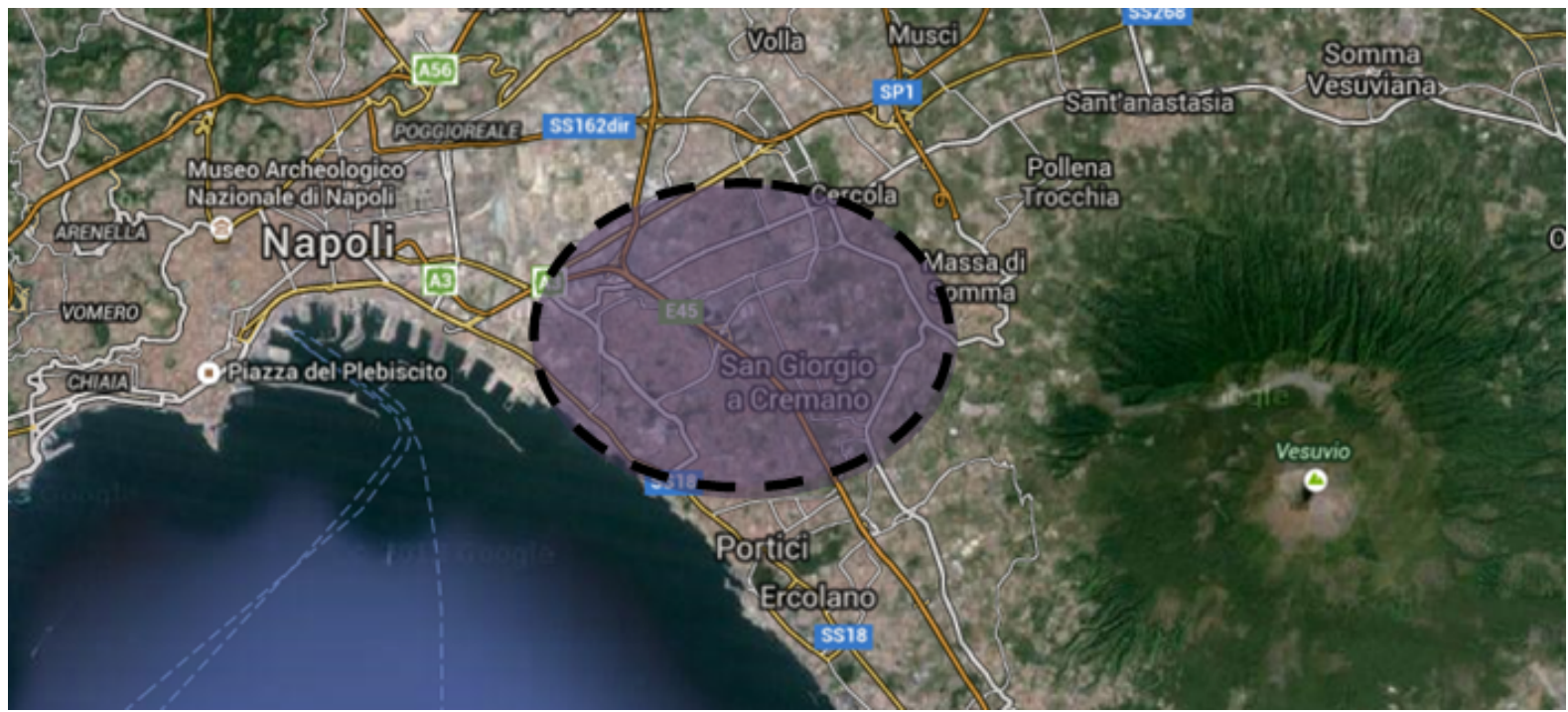

Figure 1 East Urban Area of Naples.

A certain invention disclosure ID* of TTO, was proposed to many different potential users located in the east area of Naples during 24 months and 257 of these failed because they didn't arouse interest. We consider as failure a condition in which the technology transfer instance relative to a certain ID* proposal doesn't generate a contact link of interest with the potential users.

The sample selected for this analysis is constituted by 145 SMEs of the east area of Naples and is evaluated, during the years 2013 and 2014 after the start-up of the research centre Cesma,.

Data collected have been stratified into categories of table 1.

\begin{tabular}{|c|c|}
\hline SMEs' sector & Number \\
\hline ICT & 30 \\
\hline Consulting & 20 \\
\hline Logistic \& Transportation & 55 \\
\hline Tourism & 40 \\
\hline Total & $\mathbf{1 4 5}$ \\
\hline
\end{tabular}

Table 1: SMEs Sectors of urban east area of Naples

So, the basic data on observed performance life correspond to 257 technology transfer instances (TTI), related to the same ID*. Therefore, these constitute a random sample without censoring. Among these failures, 251 TTIs could be corresponded to the market saturation and the remaining six failures are due to errors in the choice of users not suitable for the proposed technology of the invention disclosure ID*.

Let ti be the life (in TTIs) of IDi. That is, we have the observations ti, $\mathrm{i}=1,257$. The first step in life data analysis is to estimate the technology transfer failure rate (TTFR) that leads us to guess fairly well about the underlying distribution of life. Lawless (1982), Meeker and Escobar (1998), Nelson (1982). The TTFR for TTI is estimated as in the following: 
TTFR during an interval = (number of failures during the interval) / (average number of invention disclosures exposed to the risk of failure at the midpoint of the interval) $x$ (length of the interval) (Srinath, 1975).

The calculations are shown in table 2 and is plotted in Fig. 2.

\begin{tabular}{cccc}
\hline Class interval of TTIs & Number of failures & $\begin{array}{c}\text { Number of } \\
\text { completed TTIs }\end{array}$ & TTFR \\
\hline $0-10$ & 7 & 250 & 0.00276 \\
$10-20$ & 7 & 243 & 0.00284 \\
$20-30$ & 9 & 234 & 0.00377 \\
$30-40$ & 4 & 230 & 0.00172 \\
$40-50$ & 5 & 225 & 0.00220 \\
$50-60$ & 4 & 221 & 0.00179 \\
$60-70$ & 7 & 214 & 0.00322 \\
$70-80$ & 4 & 210 & 0.00189 \\
$80-90$ & 4 & 206 & 0.00192 \\
$90-100$ & 6 & 200 & 0.00296 \\
$100-110$ & 4 & 196 & 0.00202 \\
$110-120$ & 15 & 181 & 0.00796 \\
$120-130$ & 31 & 150 & 0.01873 \\
$130-140$ & 60 & 90 & 0.05000 \\
$150-150$ & 73 & 17 & 0.13645 \\
$160-170$ & 16 & 1 & 0.17778 \\
& 1 & 0 & 0.20000 \\
\hline
\end{tabular}

Table 2 Estimation of TTFR

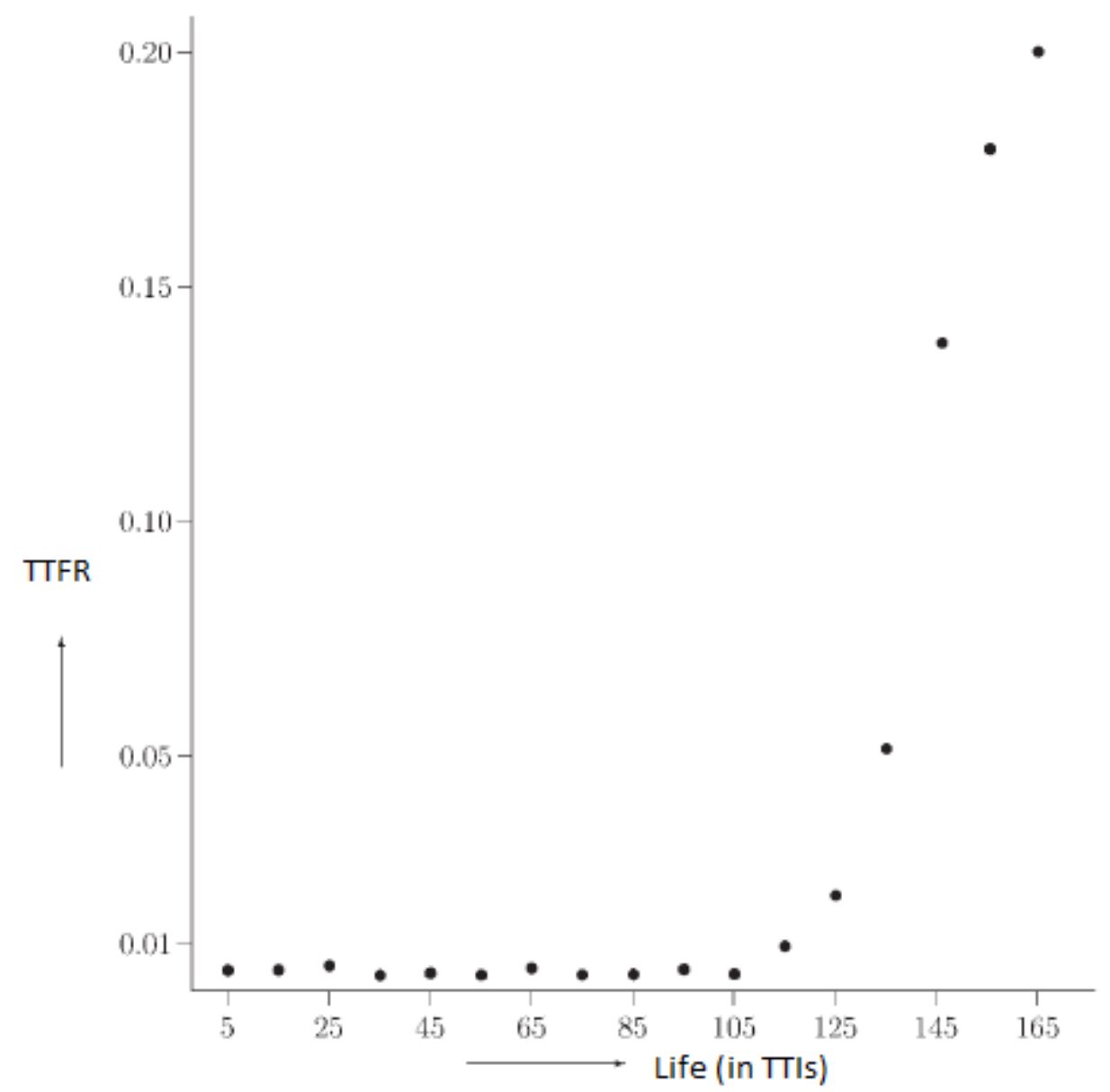

Fig. 2 Technology Transfer Failure Rate plot. Source: Manna (2004) 
We observe that the values of six ti's corresponding to the non-market saturation condition failure modes are spread over the entire range of remaining ti's, and TTFR function remains almost unaltered even when they are dropped. It is evident that (empirical) TTFR is more or less constant up to a certain time point and then increases very rapidly. This time point is referred to as wear-out point or change-point. On comparison of figure 2 with a typical bath tub curve that generally describes failure rate over the whole life-span, we conclude that just when the TTO propose a new invention disclosure, the interest of potential users is very great and so early failure condition is absent, while the period indicating constant failure rate is useful life, and the last phase describes wear-out period starting from the change-point (or wear-out point).

\section{ESTIMATION OF INVENTION DISCLOSURE LIFE}

In this section, we try to identify a suitable distribution that describes the performance life of an invention disclosure. We refer to the TTFR plot of the last section and the conclusions drawn therein. It may be observed that standard probability distributions, like Weibull distribution, log-normal distribution, or extreme-value distribution are not well suited to describe this life pattern. Therefore, we look for a function that closely resembles the observed TTFR function. We consider a piecewise linear-quadratic TTFR function $h(t)$ given by Eq. (1), where $t$ denotes the life and $\lambda$ is the constant failure rate up to the change-point $\tau$. We consider $\lambda$ constant but different according to the different field, if science and engineering or medicine, from which the TTO find the invention disclosure.

Beyond $\tau, h(t)$ is quadratic in form:

$$
h(t)= \begin{cases}\lambda & \text { if } t<\tau \\ \lambda+\beta_{1}(t-\tau)+\beta_{2}(t-\tau)^{2} & \text { if } t \geq \tau\end{cases}
$$

Hence, it is expected to represent our data well. However, we note that unless both $\beta_{1}$ and $\beta_{2}$ arepositive, the corresponding distribution function need not be non decreasing. In fact, it is found that the least-square estimates are $\widehat{\beta 1}<0$ and $\widehat{\beta 2}<0$. (The estimation procedure is discussed later). Althoughthe function given by Eq. (1) represents our empirical TTFR rate extremely well, the corresponding distribution function of life is not well defined due to the signs of $\widehat{\beta 1}$ and $\widehat{\beta 2}$. Therefore, we resort to thefollowing modified form of TTFR rate function:

$$
h(t)= \begin{cases}\lambda & \text { if } t<\tau \\ \lambda+\beta(t-\tau)^{2} & \text { if } t \geq \tau .\end{cases}
$$

The corresponding density function $\mathrm{f}(\mathrm{t})$ and distribution function $\mathrm{F}(\mathrm{t})$ are obtained by using the following relationship (Kapur and Lamberson, 1977):

$$
f(t)=h(t) \exp \left[-\int_{0}^{t} h(x) d x\right]
$$


And

$$
1-F(t)=\frac{f(t)}{h(t)}
$$

The explicit form of $f(t)$ and $F(t)$ are

$$
\begin{aligned}
f(t) & \\
{\left[\lambda+\beta(t-\tau)^{2}\right] } & \text { if } t<\tau \\
\exp \left[-\left\{\lambda t+\beta(t-\tau)^{3} / 3\right\}\right] & \text { if } t \geq \tau,
\end{aligned}
$$

$F(t)$

$$
= \begin{cases}1-\exp (-\lambda t) & \text { if } t<\tau \\ 1-\exp \left[-\left\{\lambda t+\beta(t-\tau)^{3} / 3\right\}\right] & \text { if } t \geq \tau .\end{cases}
$$

The graphical forms of $f(t)$ and $F(t)$ are shown in Appendix B, along with the moments of the distribution.

In order to estimate the parameters involved, we fit the TTFR rate function given by Eq. (2) to our data by method of least squares. Note that besides the usual parameters $\lambda$ and $\beta$, the change-point $\tau$ is also required to be estimated.

In this context, we propose the following procedure.

1. Suppose $\tau_{0}$ be a trial value of $\tau$. Divide the set of all 257 TTIs into two groups, namely, $\mathrm{G}_{1}=\left\{\right.$ TTI $\left.\quad \mathrm{i}: \mathrm{t}_{\mathrm{i}}<\tau_{0}\right\}, \mathrm{G}_{2}=\left\{\right.$ TTI $\left.\quad \mathrm{i}: \mathrm{t}_{\mathrm{i}}>\tau_{0}\right\}$.

2. Obtain LSE (least-square estimate) of $\lambda$, say $\$$ from $G_{1}$, and let $\operatorname{ESS}\left(G_{1}\right)$ be the corresponding error sum of squares. Use this estimate of $\lambda$ in $G_{2}$ and obtain $\widehat{\beta}$, the LSEof $\beta$. Let $\operatorname{ESS}\left(\mathrm{G}_{2}\right)$ be the error sum of squares in $\mathrm{G}_{2}$.

3. Denote the estimate of $\tau$ by $\$$. Select $\$=\tau_{0}$ when the sum $\operatorname{ESS}\left(\mathrm{G}_{1}\right)+\operatorname{ESS}\left(\mathrm{G}_{2}\right)$ is minimum for $\tau=\tau_{0}$. Further, the corresponding $\$$ and $\hat{\beta}$ are taken as the estimates of $\lambda$ and $\beta$ respectively.

This yields the estimates as

$\$=112$ TTIs;

$\$=0: 002522 ;$ and

$\widehat{\beta}=0: 000127$. 


\begin{tabular}{cccc}
\hline Class interval of TTIs & Observed frequency & Expected frequency & Estimated $\chi^{2}$ \\
\hline $0-10$ & 7 & 6.400 & 0.056 \\
$10-20$ & 7 & 6.241 & 0.092 \\
$20-30$ & 9 & 6.086 & 0.396 \\
$30-40$ & 4 & 5.934 & 0.107 \\
$40-50$ & 5 & 5.786 & 0.478 \\
$50-60$ & 4 & 5.642 & 0.408 \\
$60-70$ & 7 & 5.502 & 0.347 \\
$70-80$ & 4 & 5.365 & 0.290 \\
$80-90$ & 4 & 5.231 & 0.159 \\
$90-100$ & 6 & 5.101 & 0.191 \\
$100-110$ & 4 & 4.974 & 4.142 \\
$110-120$ & 15 & 8.921 & 2.510 \\
$120-130$ & 31 & 41.165 & 2.435 \\
$130-140$ & 60 & 73.366 & 6.656 \\
Above 150 & 73 & 54.035 & 0.004 \\
Total & 17 & 17.251 & 19.900 \\
& 257 & 257.000 & \\
\hline
\end{tabular}

Table 3 Test for goodness of fit for TTIs

Depending upon the values of $\lambda$ and $\beta$ both $f(t)$ as well as $F(t)$ take different forms. They are displayed in figures. 3 and 4, respectively. Given $\lambda$, a larger value of $\beta$ increases the peak of $f(t)$. Whereas, the value of $\lambda$ (for fixed $\beta$ ) decides its shape. The value of $\tau$ mainly gives the timepoint after which $f(t)$ starts increasing (see cases $b$ and $c$ of figure 3 ).

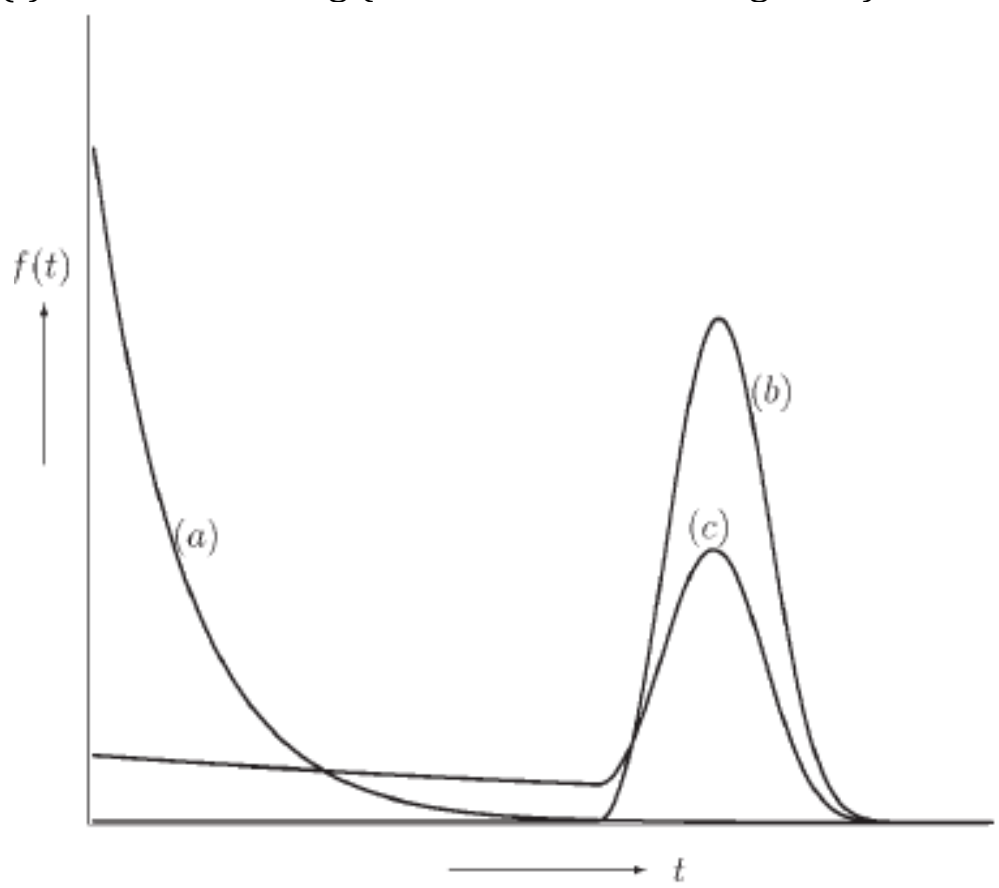

Fig. 3 Graphs of $f(t)$ for $\tau=112$ and (a) $\lambda=0.05, \beta=0.0001$ (i.e., $\lambda>>\beta$ ), (b) $\lambda=0.0001, \beta=0.0001$ (i.e., $\lambda$ very small),(c) $\lambda=0.005, \beta=0.0001$. Source: Manna (2004) 


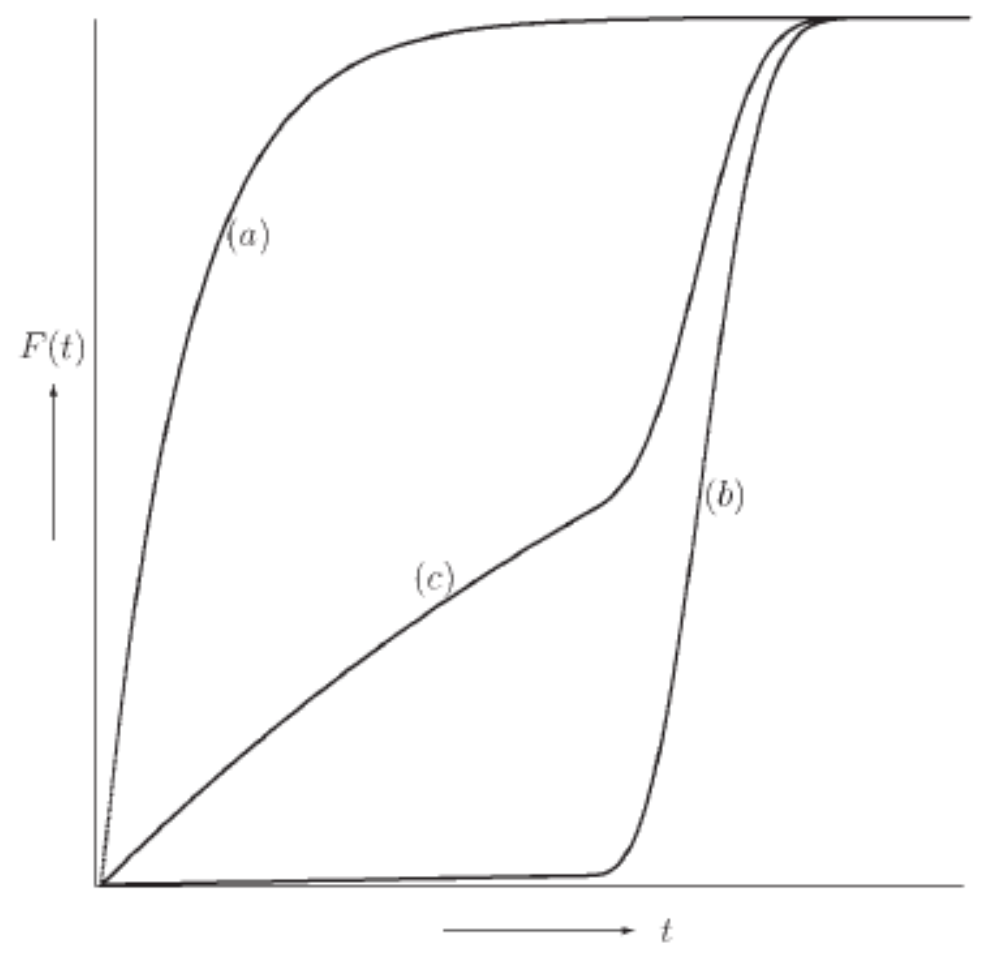

Fig. 4 Graphs of $F(t)$ for $\tau=112$ and (a) $\lambda=0.05, \beta=0.0001$ (i.e., $\lambda>>\beta$ ), (b) $\lambda=0.0001, \beta=0.0001$ (i.e., $\lambda$ very small),(c) $\lambda=0.005, \beta=0.0001$. Source: Manna (2004)

The mean $\mu$ of life can be computed as follows:

$\mu=$

And, it may be observed that $\mu>\left(1-\mathrm{e}^{-\lambda} \mathrm{x}\right) / \lambda$

Generally, the $r$ th raw moment of life is given by $\mu_{r}^{\prime}$, where:

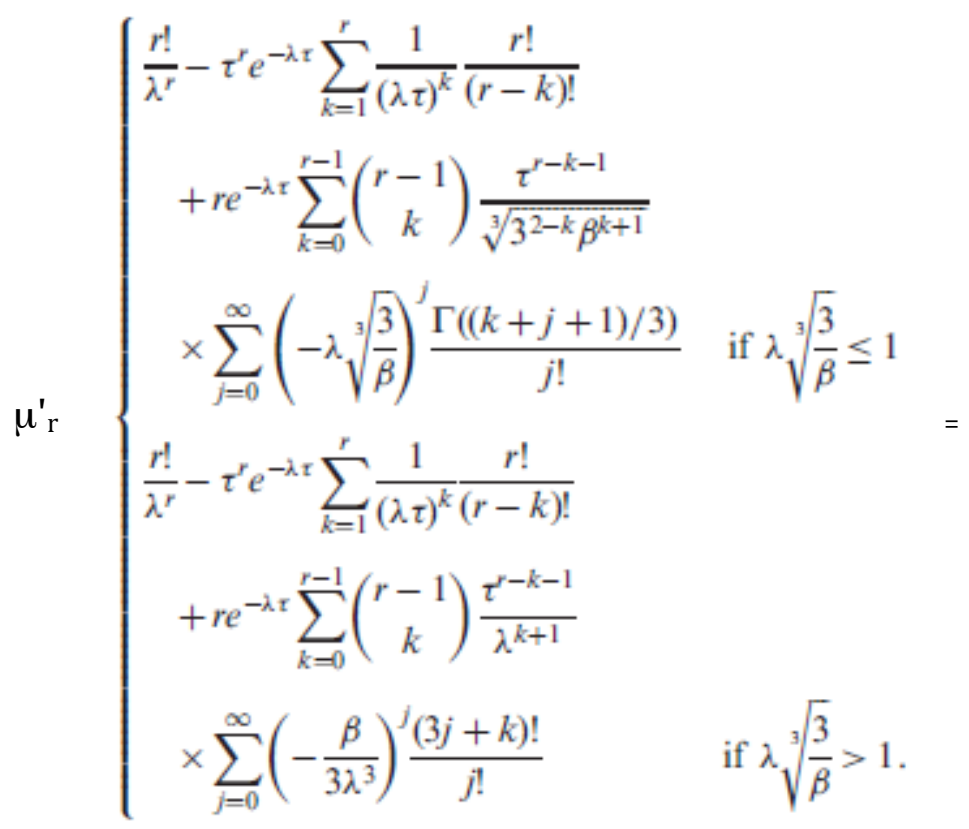

The mean $\mu$ and standard deviation oof life are then estimated as $\not t=116.20$ TTIs and $\ell=40.20$ TTIs. 
The corresponding observed values in the sample are 116.94 TTIs and 41.63 TTIs, respectively. Subsequently, the adequacy of $\mathrm{f}\left(\mathrm{t}\right.$ ), given in Eq. (5), is evaluated with a $\chi^{2}$ - test (see table 3).We conclude that $\mathrm{f}(\mathrm{t})$ describes the data quite satisfactorily. The graph for the associated technology transfer reliability function TT-R(t) is given in figure 5 .

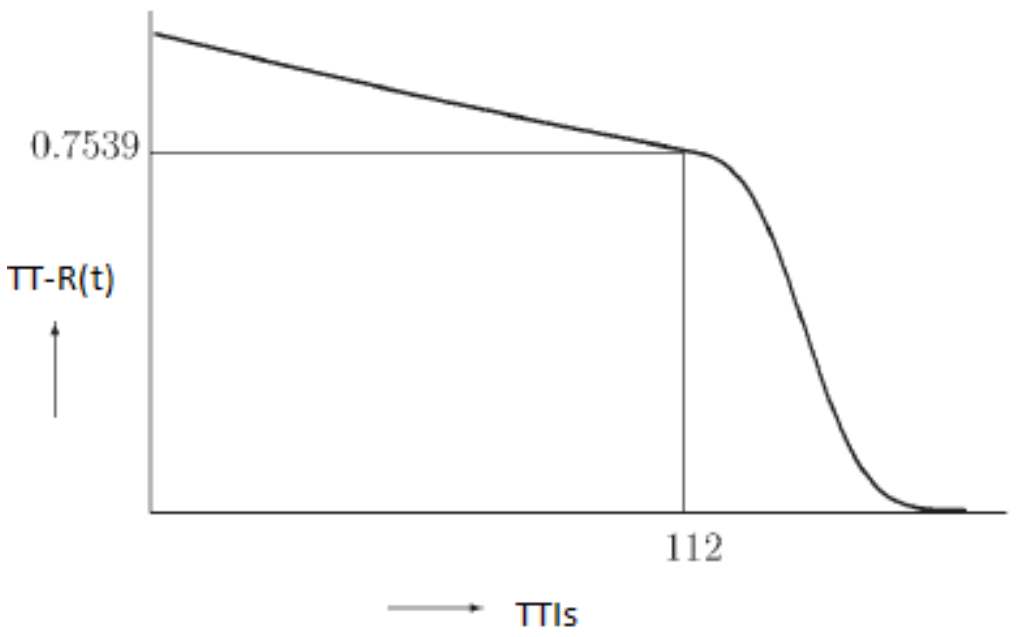

Fig. 5 Technology transfer reliability function TT-R(t). Source: Manna (2004)

\section{REPLACEMENT POLICY OF INVENTION DISCLOSURE}

It is evident that a safe replacement policy is to withdraw the ID* when it has reached the wearout point $\tau$. However, the true value of $\tau$ is unknown; we have merely an estimate of it. In such case, wedepend on its confidence interval. This is derived using the bootstrap methodology (Efron and Tibshirani, 1993). One thousand bootstrap samples are drawn from our basic data set, and change-point is estimated (following the procedure presented earlier) for each of these samples. The percentiles of $\$$, thus obtained, are presented in table 4 .

\begin{tabular}{llllll}
\hline Probability & 0.05 & 0.10 & 0.50 & 0.90 & $0 . .95$ \\
\hline \multirow{2}{*}{ Value of $\$$} & 94 & 101 & 113 & 123 & 125 \\
\hline
\end{tabular}

Table 4 Percentiles of $\$$

It is to be noted that in order to decide on the replacement time of ID*, we are interested in the lowest possible value of $\tau$. That is, a lower confidence interval for $\tau$ is of interest. A $95 \%$ lower confidence interval for $\tau$ is given by $\tau>94$ TTIs; that is, a ID* should be replaced when it has completed 94 TTIs.

The method of maximum likelihood can also be applied for estimation of the parameters. It may be observed that the corresponding likelihood function is not differentiable; therefore, we obtain the estimates numerically. As we have mentioned earlier, most researchers deal with piecewise linear TTFR rate functions. However, the procedure of BGJ (Basu et al., 1988) is quite relevant here for the estimation of changepoint, but it does not address the problem of life estimation. Minor trivial modifications are made to this procedure to suit the present problem.

Suppose that is the empirical distribution function of life, and $\mathrm{y}(\mathrm{t})=-\log [1-\xi(t)]$. Let $\mathrm{p}_{0}>0$ be very small and $p_{1}$ be a good lower bound for $F(\tau)(<1)$, where $F(t)$ is the true distribution function of life. 
Then, the estimate of $\lambda$ is given by:

$$
\bar{\lambda}=\frac{\sum t_{[]} y\left(t_{[[]}\right) /(k+1)}{-\left(\sum t_{[]} /(k+1)\right)\left(\sum y\left(t_{[i]}\right) /(k+1)\right)}
$$

Where $\mathrm{t}[\mathrm{i}]$ is the $i$ th ordered life, $\mathrm{k}=\left[\mathrm{np}_{1}\right]-\left[\mathrm{np}_{0}\right], n$ isthe total number of observations, and all the summations range over $\mathrm{i}=\left[\mathrm{np}_{0}\right]+1$ to $\left[\mathrm{np}_{1}\right]$.

Then the BGJ estimator for $\tau$ is estimated as:

$$
\overline{\boldsymbol{\tau}}=\sup \left\{t: \frac{y(t+\Delta t)-y(t)}{\Delta t}<\bar{\lambda}\right\}
$$

$\Delta t>0$ and $\bar{\lambda}$ is obtained from Eq. (7).

In order to derive the estimates, we have $n=257$,

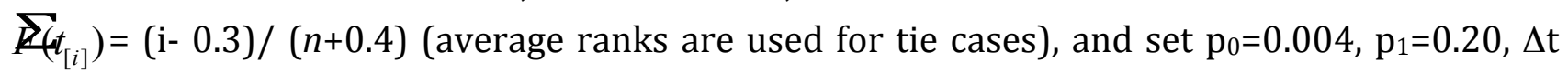
$=1$.Using Eqs. (7) And (8), we get

$\$=002445$ per TTI; and

$\$=110$ TTIs:

The estimate of $\tau$ by BGJ is obtained as $\bar{\tau}=110$ TTIs, and the 95\%lower confidence interval for $\tau$ (estimated through bootstrap method using 1000 bootstrap samples) is given by: $\tau>97$ TTIs. Hence, we find that there isalmost no discrepancy in TT replacement plan obtained from these two methods.

\section{CONCLUSION AND FUTURE WORK}

In this paper we have pointed out the importance, for geographers and TT managers, to use operative tools to control and monitor the performance of TTOs and for this aim we have studied the problem of "performance life" for the invention disclosures by TTO and determination of replacement policy. We have transposed models generally used in other field, (Manna 2004), and we have referred to the TTFR rate as a piecewise linear-quadratic function. We have proposed a procedure for estimation of technology transfer life in this situation and the approach of the present study is declined to the specific case of marginal urban area. Subsequently, the technology transfer replacement plan for an invention disclosure is derived using the confidence interval of the wear-out point of the proposed curve. As in the present case of particular invention disclosure ID*, there can be many situations where life distribution may not be easily visualized as one of the standard probability distributions. Under such circumstances, we rely heavily on the underlying TTFR function. The advantage of the proposed procedure over existing ones is that it makes direct use of the empirical TTFR function in order to identify the distribution of life. This estimation procedure is primarily based on the least square method and is applicable to general piecewise TTFR function. However, utmost care must be taken in estimation of proper distribution function of life while dealing with quadratic TTFR function.

The proposed approach provides information to the TT managers concerning the optimal choice compliance with the promotion's activity of invention disclosures of TTOs, behind as practical implications we can consider that esults of the analysis give two positive corollaries: 
first they may promote further studies in this sector because the prospective of impacts of technology transfer in urban marginal areas lends itself well to further studies not yet present, in large numbers, in the scientific literature of the field; second, they may guide both geographers, researchers and managers of local urban institutions to develop more and more geographical connections between citizens and research institutions to promote the entrepreneurial activity related to the smart services in the marginal areas.

\section{About further research}

Such authors (Anderson et al. 2007) studied the efficiency of university technology transfer and they reported some propositions, between some of them, the following:

1. Proposition 6. There are no differences in university technology transfer efficiency between private and public institutes.

2. Proposition 7. There are differences in university technology transfer efficiency between universities with medical schools and those without.

3. Further research will provide to evaluate and compare the constant failure rate 1 to verify the transposition of the previous propositions in term of the following:

4. Proposition 1. There are no differences in constant failure rate 1 of university technology transfer activities between private and public institutes.

5. Proposition 7. There are differences in constant failure rate 1 of university technology transfer activities between universities with medical schools and those without.

\section{References}

Agrawal, A., Henderson, R., (2002). Putting patents in context: exploring knowledge transfer from MIT. Management Science, 48 (1), 44-60.

Anderson T., Daim T., Lavoie F (2007). Measuring the efficiency of university technology transfer. Technovation, 27, 306-318.

Audretsch, D. B., Hulsbeck, M. \& Lehmann E. E. (2011). Regional competitiveness, university spilloversand entrepreneurial activity. Small Business Economics.

Audretsch, D. B., Keilbach, M. C., \& Lehmann, E. E. (2006). Entrepreneurship and economic growth. USA: Oxford University Press.

Baldini, N. (2006). University patenting and licensing activity: A review of the literature. Research Evaluation, 15(3), 197-207.

Basu, A. P., Ghosh, J. K., Joshi, S. N. (1988). On estimating change point in a failure rate. In: Gupta, S. S., Berger, J. O., eds. Statistical Decision Theory and Related Topics IV. Vol. 2. Springer-Verlag, 239-252.

Beise, M., Stahl, H., (1999). Public research and industrial innovations in Germany. Research Policy, 28 (4), $397-$ 422.

Bennet, J., Polkinghorne, M., Pearce, J., (1998). Quantifying the effectiveness of an academia-industry technology transfer initiative in a low prosperity region of the UK. Paper presented at the International Conference on Management of Technology.

Boyle, K., (1986). Technology transfer between universities and the UK offshore industry. IEEE Transactions on Engineering Management, 33 (1), 33-42.

Carlsson, B., \& Fridh, A.-C. (2002). Technology transfer in United States universities. Journal of Evolutionary Economics, 12(1-2), 199-232.

Chapple, W., Lockett, A., Siegel, D., Wright, M., (2005). Assessing the relative performance of U.K. university technology transfer offices: parametric and non-parametric evidence. Research Policy, 34 (3), 369-384.

Cohen, W.M., Nelson, R.R., Walsh, J.P., (2002). Links and impacts: the influence of public research on industrial R\&D. Management Science, 48 (1), 1-23. 
Falco, S. D. (2015). Measuring the Perofrmance of University Technology Transfer through the Estimation of Inventino disclosure Life: Focus on Urban Marginal Area. Archives of Business Research, 3(5), 35-40.

Colyvas, J., Crow, M., Gelijns, A., Mazzoleni, R., Nelson, R.R., Rosenberg, N., et al., (2002). How do university inventions get into practice? Management Science, 48 (1), 61-72.

Corsten, H., 1987. Technology transfer from universities to small and medium-sized enterprises-an empirical survey from the standpoint of such enterprises. Technovation 6 (1), 57-68.

Cosh, A., \& Hughes, A. (2010). Never mind the quality feel the width: University-industry links andgovernment financial support for innovation in small high-technology businesses in the UK and the USA. The Journal of Technology Transfer, 35(1), 66-91.

De Falco S. (2012) is it possible to control and optimize technology transfer process? Journal of Innovation and Entrepreneurship, 1:6.

De Falco S. (2014). Measuring the regional dimension of innovation through an economic model based on rectifying technology audits according to the AICTT-RTA protocol. Vol 2, No 6 (2014): Archives of Business Research ISSN 2054-7404.

di Gregorio, D., Shane, S., (2003). Why do some universities generate more start-ups than others? Research Policy, 32 (2), 209-227.

Efron, B., Tibshirani, R. J. (1993). An Introduction to the Bootstrap. Chapman \& Hall.

Feller, I., Ailes, C.P., Roessner, J.D., (2002). Impacts of research universities on technological innovation in industry: evidence from engineering research centers. Research Policy, 31 (3), 457-474.

Fritsch, M., \& Lukas, R. (2001). Who cooperates on R\&D? Research Policy, 30(2), 297-312.

Geuna, A., Nesta, L.J.J., 2006. University patenting and its effects on academic research: the emerging European evidence. Research Policy, 35 (6), 790-807.

Goldfarb, B., Henrekson, M., (2003). Bottom-up versus top-down policies towards the commercialization of university intellectual property. Research Policy, 32 (4), 639-658.

Goldhor, R.S., Lund, R.T., (1983). University-to-industry advanced technology transfer: a case study. Research Policy, 12 (3), 121-152.

Gombay, E. (2000). Sequential change-point detection with likelihood ratios. Statistics \& Probability Letters 49:195-204.

Gonzàles-Pernia, J.L., Kuechle, G., \& Peñaki-Legazkue I. (2011). An assessment of the determinants of university technology transfer. Economics of Innovation and New Technology.

Gürler, U ., Yenigün, C. D. Hazard Change-point Models with Truncated Data. Technical Report 2002-05, Department of Industrial Engineering, Bilkent University, Ankara, Turkey, 2002.

Heher, A., (2006). Return on investment in innovation: implications for institutions and national agencies. The Journal of Technology Transfer, 31 (4), 403-414.

Hülsbeck M., Lehmann E., Starnecker A., (2011). Performance of technology transfer offices in Germany. Journal of Technology Transfer, 38, 199-215.

Jensen, R. A., \& Thursby, M. C. (2001). Proofs and prototypes for sale: The licensing of university inventions. American Economic Review, 91(1), 240-259.

Kapur, K. C., Lamberson, L. R. (1977). Reliability in Engineering Design. John Wiley \& Sons.

Lawless, J. F. (1982). Statistical Models and Methods for Lifetime Data. John Wiley \& Sons.

Lee, J., Win, H.N., 2004. Technology transfer between university research centers and industry in Singapore. Technovation, 24 (5), 433-442.

Link, A., Rothaermel, F., \& Siegel, D. (2008). University technology transfer: An introduction to the special issue. IEEE Transactions on Engineering Management, 55(1), 5-8.

Loader, C. R. (1991). Inference for a hazard rate change-point. Biometrika 78:749-757.

Lopez, W.H., 1998. How universities can organize to support industrially relevant research effectively.

Technological Forecasting and Social Change, 57 (3), 225-228. 
Lopez-Martinez, R.E., Medeli, E., Scanl, P.A., Solerio, J.L., 1994. Motivations and obstacles to university industry cooperation: a Mexican case. R\&D Management, 24 (1), 17-32.

Lowe, R., 2006. Who develops a university invention? The impact of tacit knowledge and licensing policies. The Journal of Technology Transfer, 31 (4), 415-429.

Manna, D.K. (2004), Estimation of Life with piecewise Linear-Quadratic Hazard rate, Quality Engineering vol. 16, N.4, pp. 577-584

Matthews, D. E., Farewell, V. T. (1982). On testing for a constant hazard against a change-point alternative. Biometrics 38:463-468.

Mazzoleni, R., 2006. The effects of university patenting and licensing on downstream R\&D investment and social welfare. The Journal of Technology Transfer, 31 (4), 431-441.

McAdam, R., Keogh, W., Galbraith, B., Laurie, D., (2005). Defining and improving technology transfer business and management processes in university innovation centres. Technovation, 25 (12), 1418-1429.

Meeker, W. Q., Escobar, L. A. (1998). Statistical Methods for Reliability Data. John Wiley \& Sons.

Meoli, M., Paleari, S. \& Vismara S. (2011). Completing the technology transfer process: The IPOs and M\&As of biotech spin-offs, Small Business Economics.

Meyer-Krahmer, F., Schmoch, U., (1998). Science-based technologies: university-industry interactions in four fields. Research Policy, 27 (8), 835-851.

Mowery, D. C., \& Sampat, B. N. (2005). The Bayh-Dole Act of 1980 and university-industry technology transfer: A model for other OECD governments? Journal of Technology Transfer, 30(1-2), 115-127.

Mowery, D.C., Sampat, B.N., Ziedonis, A.A., (2002). Learning to patent: institutional experience, learning, and the characteristics of U.S. University Patents after the Bayh-Dole act, 1981-1992. Management Science, 48 (1), 73-89.

Nelson, W. (1982). Applied Life Data Analysis. John Wiley \& Sons.

Nguyen, H. T., Rogers, G. S., Walker, E. A. (1984). Estimation in change-point hazard rate models. Biometrika 71:299-304.

Owen-Smith, J., Riccaboni, M., Pammolli, F., Powell, W.W., (2002). A comparison of U.S. and European universityindustry relations in the life sciences. Management Science, 48 (1), 24-43.

Rasmussen, E., Moen, O., Gulbrandsen, M., (2006). Initiatives to promote commercialization of university knowledge. Technovation, 26 (4), 518-533.

Rothaermel, F. T., Agung S. D., \& Jiang L. (2007). University entrepreneurship: A taxonomy of the literature. Industrial and Corporate Change, Advance Access published, July 18, 2007, 1-101.

Rukhin, A. L. (1997). Change-point estimation under asymmetric loss. Statistics \& Decisions 15:141-163.

Sampat, B.N., 2006. Patenting and US academic research in the 20th century: the world before and after BayhDole. Research Policy, 35 (6), 772-789.

Shane, S., 2002. Selling university technology: patterns from MIT. Management Science, 48 (1), $122-137$.

Shane, S., Stuart, T., (2002). Organizational endowments and the performance of university start-ups. Management Science, 48 (1), 154-170.

Siegel, D.S., Thursby, J.G., Thursby, M.C., Ziedonis, A.A., (2004). Organizational issues in university-industry technology transfer: an overview of the symposium issue. The Journal of Technology Transfer, 26 (1), 5-11.

Siegel, D.S., Waldman, D., Link, A., (2003). Assessing the impact of organizational practices on the relative productivity of university technology transfer offices: an exploratory study. Research Policy, 32 (1), 27-48.

Srinath, L. S. (1975). Concepts in Reliability. Affiliated East-West Press.

Thursby, J. G., \& Thrusby, M. C. (2007). University licensing. Oxford.Review of Economic Policy, 23(4), 620-639.

Thursby, J.G., Kemp, S., (2002). Growth and productive efficiency of university intellectual property licensing. Research Policy, 31 (1), 109-124. 
Falco, S. D. (2015). Measuring the Perofrmance of University Technology Transfer through the Estimation of Inventino disclosure Life: Focus on Urban Marginal Area. Archives of Business Research, 3(5), 35-40.

Trune, D.R., Goslin, L.N., (1998). University technology transfer programs: a profit/loss analysis-A preliminary model to measure the economic impact of university licensing. Technological Forecasting and Social Change, 57 (3), 197-204.

Tseng, A. A., Raudensky, M. (2015). Performances of technology transfer activities of US universities after BayhDole Act. J. Economics, Business \& Management, 3(6), 661-667.

Van Ledebur, S. (2008). Technology transfer offices and university patenting-a review. Jena Economic Papers, 2008-033.

Vinig T. \& Lips D. (2015) Measuring the performance of university technology transfer using meta data approach: the case of Dutch universities.Journal of Technology Transfer, open access.

Zucker, L.G., Darby, M.R., Armstrong, J.S., (2002). Commercializing knowledge: university science, knowledge capture, and firm performance in biotechnology. Management Science, 48 (1), 138-153. 